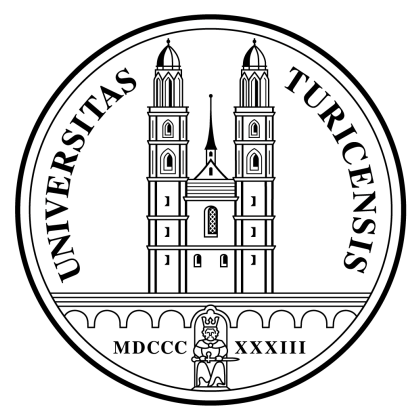

Institute for Empirical Research in Economics

University of Zurich

Working Paper Series

ISSN 1424-0459

forthcoming in: Experimental Economics

Working Paper No. 18

Efficient Contracting and Fair Play in a Simple

Principal-Agent Experiment

Vital Anderhub, Simon Gächter and Manfred Königstein

September 2000 


\title{
Efficient Contracting and Fair Play in a Simple Principal-Agent Experiment
}

\author{
Vital Anderhub, Humboldt University at Berlin \\ Simon Gächter, University of St. Gallen \\ Manfred Königstein, Humboldt University at Berlin*
}

- September 2000 -

\begin{abstract}
We study behavior within a simple principal-agent experiment. Our design allows for a large class of linear contracts. Principals can offer any feasible combination of (negative) fixed wages and incentives in the form of return sharing. This great contractual flexibility allows us to study incentive compatibility simultaneously with issues of 'fair sharing' and reciprocity, which were previously found to be important. We find a high degree of incentive-compatible behavior, but also 'fair sharing' and reciprocity. In contrast to other incentive devices studied in the literature, the incentives are 'reciprocity-compatible'. Principals recognize the agency problem and react accordingly.
\end{abstract}

Keywords: Principal-agent theory, contract theory, fair sharing, incentive contracts, reciprocity, experiments.

JEL-Codes: J33, J41, L14, C91.

*Postal addresses: Anderhub and Königstein: Department of Economics, HumboldtUniversity at Berlin, Spandauer Strasse 1, D-10178 Berlin, Germany. Gächter: University of St. Gallen, FEW-HSG, Dufourstrasse 50b, CH-9000 St. Gallen, Switzerland. E-mail addresses: anderhub@wiwi.hu-berlin.de; simon.gaechter@unisg.ch; mkoenig@wiwi.hu-berlin.de. 


\section{Introduction}

A crucial aspect of an agency relationship is that the agent does not necessarily take actions that are in the best interest of the principal. This problem is particularly severe if the principal's preferred action cannot be contractually enforced. The reason for this is that there is some asymmetric information either between the principal and the agent or between them and a third party like the courts that prevents the conclusion of enforceable contracts.

Agency problems have been formalized as principal-agent (PA) models and have been a major subject of economic theorizing especially within the last two decades (see, e.g., Holmström 1979; Shavell 1979; Grossman and Hart 1983; Hart and Holmström 1987; and Salanié 1997 for a recent textbook account). In most of these models, if contracts can not be enforced completely, the principal has to design a work contract that obeys 'incentive compatibility constraints' and a 'participation constraint'. The former are necessary to align interests between the principal and the agent because of the presumed opportunism of the agent. The latter constraint is necessary to guarantee that the agent agrees to the contract in the first place. The principal takes optimizing, selfish behavior of the agent for granted and derives the optimal contract which (i) is incentive compatible and (ii) leaves the agent just indifferent between accepting or rejecting the contract. In other words, the principal extracts the whole surplus that is created in the exchange. The agent (iii) accepts the contract and (iv) responds optimally to the incentives set in the contract.

In this paper we study the behavioral validity of these four predictions within a simple PA-game. Within this game, the principal first designs a linear contract; i.e., he may offer the agent a fixed wage and a return share. The fixed wage may be positive or negative (within some upper and lower bounds) and the return share can vary between 0 and 100 percent. A negative fixed wage is tantamount to a payment from the agent to the principal; a return share of 100 percent is tantamount to the agent possessing the whole return. Second, the agent decides on whether or not to accept the contract. Thereafter, she chooses an effort level which generates a return and causes a cost (to be beared by the agent). These three stages comprise a single base game. In the experiment the subjects play two repeated games each consisting of six base games.

Within the given restrictions any combination of fixed wage and return share constitutes a feasible contract in our experiment. If, however, the agent is selfishly motivated, a fixed-wage contract (with a zero return share) does not at all align 
interests between the principal and the agent; it leads to full shirking of the agent. Incentive compatibility requires the return share offered to the agent to be sufficiently high. In our model, the unique 'trembling hand' perfect equilibrium of the game calls for a return share of 100 percent, i.e., the agent owns the whole return for which he pays a price (i.e., a negative fixed wage) that amounts to the generated surplus. However, this solution as well as all subgame perfect equilibria of the game are questionable from the viewpoint of fairness because the principal receives all surplus.

The benchmark for our analysis are some empirical observations made in the last decade of experimental research on people's social motivations in bargaining contexts and in cooperation games. For our purposes two sets of results are particularly relevant. First, previous research has shown that reciprocity can be a very powerful contract enforcement device (Fehr, Gächter and Kirchsteiger 1997). Provided the principals do not seize the whole surplus, agents are on average willing to provide effort levels that exceed their best reply levels. This result has by now been replicated several times in different games and under different institutions (see, e.g., Güth, Klose, Königstein, and Schwalbach 1998; and Fehr and Gächter 1998 for an overview). Moreover, reciprocal behavior is not restricted to the laboratory, but can be observed in the field as well (see, e.g., Bewley 1999). The observation of reciprocity is important for agency models, because (i) it shows that under certain conditions the shirking problem is less severe than predicted and (ii) there may be important interaction effects of reciprocity and the incentivecompatibility constraint (see Fehr and Gächter 2000).

A second set of results, which might be informative about the behaviorally relevant participation constraint, comes from ultimatum games. In this game, as well as in most agency models, it is predicted that the principal appropriates the whole surplus. However, as is by now well-known (see Davis and Holt 1993 and Roth 1995 for overviews), subjects reject allocations that give them only a fraction of the pie.

These observations raise several interesting questions that we want to investigate in this paper. How do agents respond to the incentives set in the contract? Given that people are often reciprocally motivated, how does this influence agents' behavior under incentive contracts? Are incentive contracts detrimental to reciprocal behavior as it is suggested in a recent paper by Fehr and Gächter (2000)? In turn, if agents are less opportunistic than assumed by standard theory, what kind of contracts do principals design? To what extent do they rely on incentive contracts? Does the result that people reject unfair offers carry over to more com- 
plex contractual arrangements? In other words, what is the behaviorally relevant participation constraint in an agency relationship? Given that many (but not all) people are fair-minded and willing to reciprocate favors, it is important to understand how social motivations affect behavior under more complex incentive systems. Our study is among the first to extend isolated previous investigations on bargaining and reciprocity to the realm of agency problems.

In contrast to most previous experiments, in our design principals can choose among a very large number of contracts - including pure fixed-wage contracts, pure incentive contracts, and any mixture of incentive and fixed-wage contracts; agents can select among a large set of effort levels. This feature allows us to answer the above questions at one fell swoop. Within one design we can investigate the relevance of fine-tuned incentive contracts, 'fair sharing', as well as the principles which are behind effort choices.

Our most important results, presented in detail in sections 3 and 4, are as follows. In line with economic predictions, principals offer incentive compatible return shares and ask for negative fixed wages in many cases. Agents choose best reply effort levels in many cases, i.e., we find optimal effort decisions on and off the equilibrium path. Deviations from the individually optimal effort level can be explained by reciprocity. Agents who receive generous contracts are more likely to increase their effort above the best reply level than agents who receive greedy offers. Thus, in contrast to the incentive contracts studied in Fehr and Gächter (2000), the incentives set in our experiment leave reciprocal motivations intact. However, agents are also prepared to reject 'unfair' contracts. Thus, the observations from the ultimatum game carry over to our principalagent experiment. The behaviorally relevant participation constraint is one that involves fair sharing between the principal and the agent.

Our paper contributes to the behavioral investigation of agency problems. In this respect we complement empirical investigations that use naturally occurring data on issues of incentive contracting (see Prendergast 1999 for a comprehensive overview of this literature). However, there are by now not many investigations that study the behavioral elements that make up a contractual solution of an agency problem. The papers that are closest to ours in this respect are the experimental studies of Berg, Daley, Dickhaut, and O'Brien (1992); Epstein (1992); Güth, Klose, Königstein, and Schwalbach (1998); and Keser and Willinger (2000) who all study contract design and agents' behavior in moral hazard situations. Güth, Königstein, Kovács, and Zala (1999) study a PA-game with multiple 
agents. $^{1}$

In section 2 we present the game underlying our study, its theoretical solution and the applied experimental procedures. Thereafter we present our experimental data on contract design (section 3) and on the behavior of agents (section 4). Section 5 concludes.

\section{The Experimental Design}

\subsection{The game}

In the experiments we implemented a finitely repeated game that consisted of six repetitions of the following base game between two players, a principal $P$ and an agent $A$. First, the principal designs a work contract and makes a 'take it or leave it'-offer to the agent. Secondly, the agent either accepts or rejects the contract and, thirdly, chooses her work effort. In detail, the three stages and the parameters of the base game in period $t$ are as follows:

Stage 1: $P$ chooses a work contract $w_{t}=\left(f_{t}, s_{t}\right)$ that consists of two components, a fixed wage $f_{t}$ and a return share $s_{t} . P$ also states a 'suggested work effort' $\tilde{e}_{t}$ which is not binding for $A$ 's choice later on. ${ }^{2}$ The work contract and the suggested work effort have to obey the following restrictions:

$$
\begin{aligned}
& f_{t} \in\{-700,-699, \ldots,+700\} \\
& s_{t} \in\{0,0.01, \ldots, 1\} \\
& \tilde{e}_{t} \in\{0,1, \ldots, 20\} .
\end{aligned}
$$

In period $t=1$ the principal is allowed to design up to two work contracts (and to suggest a work effort for each contract).

\footnotetext{
${ }^{1}$ Other PA-studies which are, however, less closely related to ours are: Bull, Schotter and Weigelt (1987) who test the incentive effects of piece rate and tournament payment schemes; Nalbantian and Schotter (1997), who investigate various contracts to provide group incentives; Hackett (1993), who studies incomplete contracting, and Chaudhuri (1998), who investigates ratchet effects in a principal-agent relationship. Plott and Wilde (1982); DeJong, Forsythe, and Lundholm (1985); and DeJong, Forsythe, Lundholm and Uecker (1985) study moral hazard problems with multiple buyers and sellers.

${ }^{2}$ There are two reasons for the design feature of asking principals to state $\tilde{e}_{t}$. (i) It allows for a 'rationality check' of $P^{\prime} s$ contract offer and to find out what $P$ aims at. (ii) An exact calculation of $P^{\prime} s$ suggested surplus sharing (see Section 3.3) is possible.
} 
Stage 2: $A$ may either accept $\left(\delta_{t}=1\right)$ or reject $\left(\delta_{t}=0\right)$ the contract offered by $P$ (in $t=1$ she may accept one of the two offered contracts or reject both). This decision determines the 'implemented contract'. For $\delta_{t}=1$ the implemented contract is equal to the offered contract (one of the offered contracts in $t=1$ ). In case of $\delta_{t}=0$ the implemented contract is equal to $\bar{w}=(0,0)$, the 'status quo contract'.

Stage 3: $A$ chooses work effort $e_{t}$ with

$$
e_{t} \in\{0,1, \ldots, 20\} \text {. }
$$

The agent has complete effort discretion, i.e., she is not restricted by $\tilde{e}_{t}$ suggested by the principal. ${ }^{3}$

The repeated game proceeds by $P$ getting informed about $\delta_{t}$ and $e_{t}$ after $A$ 's effort choice. Then, either the next period follows (if $t<6$ ) or the game ends (if $t=6)$.

$A$ 's work effort $e_{t}$ determines the return according to the return schedule $r_{t}=$ $r\left(e_{t}\right)=35 e_{t}$. The players' repeated game payoffs are the sum of the following base game payoffs:

$$
\begin{aligned}
& \pi_{t}^{P}=\left(1-s_{t}\right) \cdot r_{t}-f_{t} \\
& \pi_{t}^{A}=s_{t} \cdot r_{t}+f_{t}-c_{t}
\end{aligned}
$$

with $s_{t}$, and $f_{t}$ according to the implemented contract, the return $r_{t}$, and cost of work effort $c_{t}=c\left(e_{t}\right)$. The cost function $c\left(e_{t}\right)$ is piecewise-linear, increasing in $e_{t}$, and convex ${ }^{4}$ :

$$
c\left(e_{t}\right)=\left\{\begin{aligned}
5 e_{t} & \forall e_{t}=0, \ldots, 4 \\
-20+10 e_{t} & \forall e_{t}=5, \ldots, 8 \\
-60+15 e_{t} & \forall e_{t}=9, \ldots, 12 \\
-120+20 e_{t} & \forall e_{t}=13, \ldots, 16 \\
-200+25 e_{t} & \forall e_{t}=17, \ldots, 20
\end{aligned}\right.
$$

For our purposes, this type of cost function has some useful properties which will be discussed later on. In the following we turn to the game-theoretic solution of this game, and then discuss some important features of our design.

\footnotetext{
${ }^{3}$ Technically, A also has to make an effort choice if she has declined $P^{\prime} s$ contract offer.

${ }^{4}$ For a tabular representation of this cost function as it was presented to the subjects, see the instructions in the Appendix.
} 


\subsection{Game-theoretic solution}

The game-theoretic solution we now derive assumes rationality and selfishness of all players. We start by characterizing the set of subgame perfect equilibria of the base game in $t=6$. For a given implemented contract $w_{6}$ the agent maximizes (2.2) by choice of $e_{6}$. Her best reply effort function $\hat{e}_{6}\left(s_{6}\right)$ satisfies:

$$
\hat{e}_{6} \equiv \arg \max _{e_{6}} \pi_{6}^{A}
$$

In contract theory this condition is known as the 'incentive compatibility constraint'. We refer to $\hat{e}_{t}$ as the 'conditionally rational effort choice'. It is the effort level that equates $A$ 's marginal return and her marginal cost. Since marginal return is constant and marginal cost is a step function, one can easily derive the conditionally rational effort choices as a function of the return share $s_{6}$ (see figure 1 and table 1). Thus, the piecewise-linear specification of the cost function allows for only six different effort levels that might be conditionally rational. In the data analysis below, this feature will make it easy to determine whether agents choose conditionally rational (i.e., best response) effort levels.

\section{Insert figure 1}

\begin{tabular}{cc}
\hline \hline $\begin{array}{l}\text { Return Share } \\
\left(s_{6}\right)\end{array}$ & $\begin{array}{l}\text { Conditionally Ra- } \\
\text { tional Effort }\left(\hat{e}_{6}\right)\end{array}$ \\
\hline $0 \leq s_{6}<\frac{1}{7}$ & 0 \\
$\frac{1}{7} \leq s_{6}<\frac{2}{7}$ & 4 \\
$\frac{2}{7} \leq s_{6}<\frac{3}{7}$ & 8 \\
$\frac{3}{7} \leq s_{6}<\frac{4}{7}$ & 12 \\
$\frac{4}{7} \leq s_{6}<\frac{5}{7}$ & 16 \\
$\frac{5}{7} \leq s_{6} \leq 1$ & 20 \\
\hline \hline
\end{tabular}

TABLE 1: Conditionally rational (i.e., best response) effort choices. Note that figure 1 suggests that $\hat{e}_{6}$ is not unique for $s_{6} \in\left\{\frac{1}{7}, \frac{2}{7}, \frac{3}{7}, \frac{4}{7}, \frac{5}{7}\right\}$. However, within the experiment $s_{6}$ could be chosen only in increments of 0.01 such that non-uniqueness was impossible.

Before deciding upon an effort level, $A$ has to choose whether to accept or to reject the offered work contract. A rejection $\delta_{6}=0$ means that the status quo contract 
$\bar{w}=(0,0)$ becomes effective and that by her subsequent choice of $\hat{e}_{6}=0$ she can guarantee herself a payoff of at least zero. Accordingly, $\delta_{6}=1$ if and only if

$$
\pi_{6}^{A}\left(\hat{e}_{6}\right) \geq 0
$$

which will be referred to as the 'participation constraint'. Thus, the principal's problem is described as follows:

$$
\max _{\hat{e}_{6}, f_{6}, s_{6}} \pi_{6}^{P}
$$

subject to (2.3) and (2.4).

Given the participation constraint is satisfied, (2.3) says that effort solely depends on $s_{6}$. Furthermore, note that multiple return shares may lead to the same effort and that optimal behavior requires for $P$ to induce a given effort at minimal cost (see, e.g., Grossman and Hart 1983). Therefore, choosing $\hat{f}_{6}$ such that (2.4) holds with equality implies that every $\left(\hat{f}_{6}, s_{6}\right)$ induces $e_{6}=\hat{e}_{6}\left(s_{6}\right)$ at minimal cost. However, this also implies that the principal captures all the surplus. Thus, maximizing $\pi_{6}^{P}$ implies surplus maximization and one easily finds that this is the case for all $s_{6} \geq \frac{5}{7}$. In summary, the paths of all subgame perfect equilibria (SPE) $\left(f_{6}^{*}, s_{6}^{*}, e_{6}^{*}\right)$ are:

$$
\begin{aligned}
& f_{6}^{*}=300-700 s_{6}^{*} \\
& s_{6}^{*} \in\left[\frac{5}{7}, 1\right] \\
& e_{6}^{*}=20 .
\end{aligned}
$$

All SPE are payoff equivalent leading to $\pi_{6}^{P}=400$ and $\pi_{6}^{A}=0$. Invoking equilibrium refinement one can show that the unique path of all perfect equilibria (see Selten 1975) is characterized by $f_{6}^{*}=-400, s_{6}^{*}=1, e_{6}^{*}=20$; i.e., the principal 'sells the return to the agent' at a price that equals the return that is generated by $e_{6}^{*}=20 .^{5}$

This is the solution for period 6. By backward induction it follows that the solutions for periods 1 to 5 are equivalent: Note that in $t=5$ any long-term agreement that specifies punishment (in $t=6$ ) in case of deviations (in $t=5$ ) is not subgame perfect. So, the solution is as in $t=6$. This reasoning goes through all periods.

\footnotetext{
${ }^{5}$ For all $s_{6}^{*}<1$, a 'trembling hand' effort choice of the agent reduces the principal's expected payoff.
} 


\subsection{Discussion of the design}

The present design reflects our main goal to investigate the principals' choice of contracts as well as the agents' behavior in the most simple but yet general enough environment that allows for a test of main elements of proposed solutions of agency problems. In particular the design gives us the opportunity to check to what extent contract design takes incentive compatibility and a participation constraint into account. It also allows us to observe the agents' (incentive compatible) behavior when confronted with a particular contract. However, our game has some specific features that distinguishes it from general PA-games and we briefly want to discuss some of these aspects.

First, the space of feasible contracts among which the principal can choose is restricted to the space of linear contracts. This is a restriction compared to the standard PA-framework (see, e.g., Grossman and Hart 1983). However, within the space of linear contracts, incentive compatible contracts that induce efficiency are feasible (and optimal).

Second, in contrast to most PA-models, effort in our model is observable. In this case economic theory suggests that the optimal contract imposes high punishments on $A$ for effort choices that are suboptimal from $P$ 's perspective. However, with limited liability, or if effort is not verifiable to a court, such contracts are not enforceable. Our restriction of the set of feasible contracts essentially plays an equivalent role. Contracts that impose high punishments for deviating behavior are infeasible. Thus, despite observable effort, we preserve some general features of PA-games with non-observable effort: The agent can deviate from the required effort without being punished; a pure fixed-wage policy induces a rational and selfish agent to shirk; and when designing a work contract the principal has to take incentive effects into account.

Last, our model is non-stochastic. Our design has the advantage that we have modelled an agency problem in which we can investigate behavior without having to deal with risk preferences and the cognitive complexities that go along with the introduction of stochastic outcomes. ${ }^{6}$

\footnotetext{
${ }^{6}$ Theoretically, under the assumption of von Neumann-Morgenstern preferences, there are experimental techniques that allow for the control of risk preferences (see Berg et al. 1986 for a general statement). However, there is a lot of experimental evidence that subjects are not expected utility maximizers (see Camerer 1995 for a survey of results). Therefore, some researchers have doubts on the validity of these techniques. For example, Selten, Sadrieh, and Abbink (1999) present experimental test results that show that these techniques do not at all work in a variety of economic decision situations. Loomes (1998) points in a similar
} 
Linear contracts that are akin to the ones investigated in this paper (i.e., that use some combination of fixed payments and return shares) can be found in reality. For example, they are used in sharecropping (see, e.g., Alston and Higgs 1982), in franchising (see e.g., Mathewson and Winter 1985); between cab owners and cab drivers (e.g., Camerer, Babcock, Loewenstein and Thaler 1997); and between authors and publishers or between actors and producers (for an example from the motion pictures industry see Chisholm 1997). Prendergast (1999) provides a comprehensive survey on empirical studies that investigated (linear) incentive contracts. A theoretical discussion of linear contracts is given by Holmström and Milgrom (1987) and, in the context of sharing contracts, by Bhattacharyya and Lafontaine (1995) .

Linear contracts are simple. This is an advantage both in reality as well as for the purposes of our experimental investigations. Linear contracts can be easily understood by experimental subjects, which increases control. It should be noted, however, that the space of contracts we allow for is actually quite large compared to other experimental studies. For instance, in Berg et al. (1992) and Epstein (1992) contracts had to be chosen among three alternatives. In our experiment the principal can design contracts with every mixture of fixed wages $f_{t}$ and return shares $s_{t}$. For example, a contract of the form $w_{t}=\left(s_{t}=0, f_{t}>0\right)$ means that the principal just offers a fixed wage to the agent and no return share at all. At the 'opposite extreme' a contract of the form $w_{t}=\left(s_{t}=1, f_{t}<0\right)$ is tantamount to 'selling the return' to the agent at a selling price of $f_{t}$. Furthermore, all 'mixed contracts' $w_{t}=\left(0<s_{t}<1, f_{t} \gtreqless 0\right)$ are possible (within the given limits set for $f_{t}$ ). This great flexibility in contract design allows us to study the importance of incentive compatibility simultaneously with issues of 'fair sharing' and reciprocity in one experimental design. In this respect our study is among the first to extend isolated previous investigations on bargaining and reciprocity to the realm of agency problems.

\subsection{Experimental procedures}

The experiment comprised four sessions that were conducted at the University of Zürich. The participants were 94 volunteer students with various backgrounds (except economics). They were all recruited from a large data base. After subjects arrived at the laboratory, they were randomly allocated to their roles as principals

direction. Keser and Willinger (2000) discuss these arguments in the context of their principalagent experiment. 
or agents, respectively. In the experiments the principals were called 'participant $\mathrm{X}$ ' and the agents were called 'participants Y'. Then subjects had to read the instructions (a translation can be found in the Appendix). Except for some rolespecific wordings, the instructions were exactly the same for both the principal and the agent. Subjects also had to answer a set of control questions to test for their understanding of payoff calculations. The experiments did not start before all subjects had answered all questions correctly. Each subject played two repeated games (referred to in the sequel as RG1 and RG2) with no role switch. It was explained to the subjects that all decisions will be taken anonymously and that identities will never be revealed. At the beginning of RG1 it was publicly announced that subjects will play a repeated game with six periods with the same opponent. At the end of RG1 subjects were informed that they will play a second repeated game (RG2) of six periods with a different opponent and again with no role switch.

The experiments were computerized and conducted with the help of the experimental software 'z-Tree' developed by Fischbacher (1999). Subjects were separated from each other by blinders and matched anonymously via a computer network. They never learned the identity of their opponent players. Each session took about one hour. The average payoff per subject was about 40 Swiss francs (roughly $\$ 33$ at the time of the experiment and including a show up fee of 15 Swiss francs).

\section{Contract design}

We present the results of our experiments as follows. First we discuss the features of contract design; i.e., offered fixed wages and return shares as well as suggested efforts. Furthermore, we investigate surplus sharing as suggested by principals. Basically, we do that by looking at the raw data without providing statistical tests. Then we turn to the analysis of the agents' behavior, their decisions to reject or accept an offer as well as their effort choices. Here, we will state three hypotheses for which we provide rigorous statistical tests. We will summarize all our findings as 'Observations'.

\subsection{Distributions of fixed wages, return shares and suggested effort}

Figures $2 \mathrm{a}$ to $2 \mathrm{c}$ display the empirical distributions of fixed wages and return shares as offered by the principals, as well as their suggested work efforts. 


\section{Insert figures $2 \mathrm{a}$ to $2 \mathrm{c}$}

We see that the majority of principals (about 70 percent) offered negative fixed wages. $^{7}$ About $2 / 3$ of all contracts exhibited return shares of $s>71$ percent. Remember that this is what incentive compatibility suggests. Looking at the suggested work efforts we find overwhelming evidence for efficiency; i.e., by far most principals (more than 82 percent) aimed at inducing an efficient effort choice (i.e., $\tilde{e}_{t}=20$ ). In the following we will refer to these contracts as 'efficiency contracts'. Comparing suggested work efforts and return shares one observes that the fraction of efficiency contracts is higher than the fraction of incentive compatible return shares. This indicates that at least some principals aimed at efficiency without providing proper monetary incentives.

Table 2 reports that the principals' choices do not change much from early to later periods and between RG1 and RG2. It reports the fraction (in \%) of choices $f<0, s>71 \%$ and $\tilde{e}=20$ for periods 1 and 2 versus periods 5 and 6 for both repeated games.

\begin{tabular}{ccccc}
\hline \hline Game & Periods & $f<0$ & $s>71 \%$ & $\tilde{e}=20$ \\
\hline RG1: & 1,2 & 66.0 & 58.5 & 83.0 \\
& 5,6 & 71.3 & 63.8 & 86.2 \\
RG2: & 1,2 & 75.5 & 67.0 & 87.2 \\
& 5,6 & 76.6 & 64.9 & 77.7 \\
\hline \hline
\end{tabular}

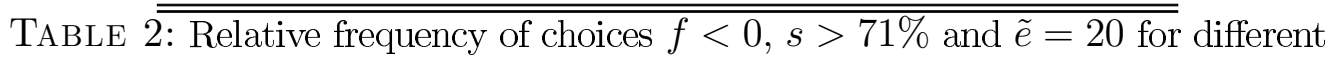
periods and both repeated games.

We summarize these findings in the following observations.

Observation 1: In most cases the offered return share is in the range predicted by the subgame perfect equilibria.

Observation 2: Principals aim at inducing efficient effort $\left(\tilde{e}_{t}=20\right)$.

Observation 3: Most contracts exhibit a negative fixed wage.

These results suggest that the principals clearly recognized the incentive problem. In the following, we take a closer look at the types of contracts the principals actually designed.

\footnotetext{
${ }^{7}$ Note that we report the contracts for all base games. Since each of 47 principals played 12 base games this makes 564 contracts.
} 


\subsection{Types of contracts}

Remember that principals could offer contracts that contained any feasible combination of fixed wages and return shares. Table 3 reports which types of contracts were offered in RG1, respectively RG2. Pure fixed-wage contracts were very rare in RG1 and were never chosen in RG2. The majority of offered contracts is of a 'mixed' type. Interestingly, a stable share of at least 24 percent of the contracts combined positive shares with non-negative fixed wages (which, under the standard assumption do not have any incentive effect). The 'trembling-hand' perfect equilibrium predicts 'sell the firm' (i.e., $s=1$ ), which describes up to thirty percent of all contracts. ${ }^{8}$ We keep these results as

Observation 4: 'Selling the firm' (i.e., $s=1$ ) occurs in about 30 percent of the cases. Roughly 70 percent of all contracts are of a 'mixed' type. Of those, at least a quarter contains positive fixed wages.

A comparison of RG1 and RG2 reveals, furthermore, that contract design was relatively stable across periods and repeated games.

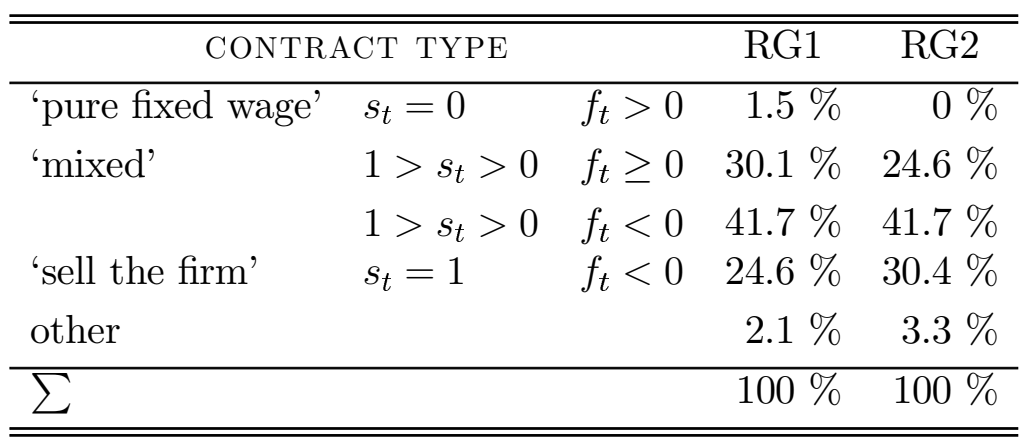

TABLE 3: Relative frequency of different contract offers in both repeated games.

A necessary condition for the agent to accept the contract is that the agent's 'participation constraint' (i.e., 2.4) is satisfied. To check this, we determined the maximal payoff that the agent could get given the offered contract. Thus, we calculated the agent's payoff by assuming a conditionally rational effort choice.

\footnotetext{
${ }^{8}$ For simplicity of exposition we concentrate in table 2 on 'pure fixed wage', 'mixed', and 'sell the firm' contracts. Of course the latter are just a subset of the SPE contracts described in Section 2.2; all SPE contracts other than $s=1$ are contained in the category 'mixed' contracts.
} 
Violations of the participation constraint (i.e., cases in which the maximal payoff the agent could achieve was negative) occurred only in 13 out of 564 cases (i.e., in 2.3 percent of the contracts). Hence, these results support

Observation 5: Almost all offered contracts satisfy the participation constraint.

According to the theoretical prediction, the participation constraint can be satisfied even with a very unequal distribution of the surplus. In the following subsection we present the results of the actually offered surplus sharing by the principal.

\subsection{Suggested surplus sharing}

The game theoretical solution under the assumption of rationality and selfishness suggests the following linear relation between fixed wages and return shares (see section 2.2):

$$
f_{t}=300-700 s_{t} \quad \forall s_{t} \geq \frac{5}{7}
$$

This implies that the principal 'sells at least 5/7of his asset' and demands the whole surplus that is created by $A^{\prime} s$ rational effort choice as the price for selling his asset. ${ }^{9}$ Figure 3 is a scatter plot of all observed combinations of return shares and fixed wages. It clearly suggests a negative tradeoff between the two contract components, at least for $s_{t} \geq 72$ percent $>\frac{5}{7}$ (note that in the experiment $s_{t}$ had to be an integer number between 0 and 100).

\section{Insert figure 3}

Since the observations 1 to 3 are qualitatively in line with economic theory, one might ask whether principals indeed tried to extract the whole surplus from the agent. However, in general, this is not the case. The solid line that is drawn in figure 3 displays equation (3.1). It represents the combinations of fixed wage and return share at which the agent receives zero income given he chooses efficient effort. Obviously, most observations lie above this line; i.e., for a given return share the fixed wage offered to the agent was higher than the rational fixed-wage level. This implies that firms do not fully extract the created surplus. It holds in almost all cases.

\footnotetext{
${ }^{9}$ More generally, the generated surplus in period $t$ that can be shared between $P$ and $A$ is $\pi_{t}^{P}+\pi_{t}^{A}=35 e_{t}-c\left(e_{t}\right)$.
} 
The broken line in figure 3 represents contracts at which the efficient surplus is split 50-50 between both players. Thus, most contracts offer the agent a share between 0 and 50 percent of the efficient surplus. This is also shown in figure 4 where we look at the surplus distribution from yet another angle. It depicts the 'implied surplus distribution' between the principal and the agent for all efficient contracts. Specifically, the figure displays the surplus share of the agent as it is implied by the offered work contract. ${ }^{10}$

\section{Insert figure 4}

The mode of the distribution is at the equal split and almost all shares are between zero and 0.5. Thus, in the majority of cases, the principals offer a 'fair' split of the pie in the following sense: The payoff distribution that results if the agent follows the suggestion of the principal and chooses efficient effort, is less asymmetric than the rather uneven payoff distribution that is theoretically predicted. Note that this does not preclude that the suggestion of the principal favors himself relative to the agent. These results closely resemble the above mentioned findings in ultimatum bargaining games and provide support for

Observation 6: Surplus sharing suggested by principals is less asymmetric i.e. more fair - than predicted by the theoretical solution.

In summary, the principals' contract offers are largely in the direction predicted by standard economic theory. In particular, in the overwhelming number of cases, the offered contracts satisfy the participation constraint and contracts contain a strictly positive return share. However, quantitatively, there are some important deviations from standard predictions. Many contracts contain return shares that are 'too low', as well as positive fixed wages that, under the maintained assumptions of rationality and selfishness, do not have any incentive effects. Moreover, most offered surplus shares are much more equal than predicted.

In the next section we turn to the behavior of the agents. We first investigate their acceptance decisions and then present results on the agents' actual effort choice dependent on the offered contract.

\footnotetext{
${ }^{10}$ The agent's surplus share is evaluated based on the terms of the offered contract and assuming that the agent indeed chooses efficient effort (as suggested).
} 


\section{Behavior of Agents}

\subsection{Acceptance of contracts}

Remember that about 97 percent of the offered contracts satisfied the 'participation constraint'. Despite this, 112 contracts out of 551 contracts that satisfied the participation constraint, were rejected by the agents. This is in clear violation of standard economic theory that predicts a rejection if and only if the participation constraint is violated.

An important question is, therefore, why agents rejected the offered contract in 20 percent of the cases. Results from numerous studies on ultimatum games offer important hints. For example, Slonim and Roth (1998) have shown that in the ultimatum game the acceptance rate of the responder was positively correlated with the relative payoff she received. In the context of our principal-agent game this result suggests that acceptance behavior is related to the offered surplus share. We formulate this intuition in the following

Fairness-Hypothesis: The influence of the agent's surplus share on her acceptance rate is positive.

To test this hypothesis, we estimated a logit regression model with the agent's acceptance decision $(1=$ acceptance, $0=$ rejection $)$ as dependent variable and the agent's surplus share as explanatory variable. Only contracts that satisfy the participation constraint enter the regression. The agent's surplus share is determined as her payoff relative to the surplus, given that she chooses a conditionally rational effort level. Thus, this model proposes that the agent looks at the split of income between the principal and herself that will result if she chooses her income maximizing effort level. The null hypothesis, derived from standard arguments, is that there is no correlation between the surplus share and the acceptance rate. The estimation results are contained in table 4 . Figure 5 illustrates the acceptance rate as a function of the offered surplus share. 


\begin{tabular}{lrrc|lcc}
\hline \hline & \multicolumn{3}{c|}{ RG1 } & \multicolumn{3}{c}{ RG2 } \\
Variable & Coeff. & S.E. & $P$ & Coeff. & S.E. & $P$ \\
\hline Constant & -1.08 & 0.46 & 0.000 & -1.41 & 0.51 & 0.005 \\
Surplus Share & 6.49 & 1.27 & 0.019 & 7.54 & 1.41 & 0.000 \\
Model & & & & & & \\
$-2 L L$ & 231 & & & 241 & & \\
$-2 L L$ (restr.) & 267 & & & 278 & & \\
$\chi^{2}$ & 36 & & & 37 & & \\
$N$ & 263 & & 275 & \\
\hline \hline
\end{tabular}

TABLE 4: Logit regression of the agent's acceptance decision on her surplus share. (Note that 13 observations are missing. These are cases in which the surplus is zero, so that the surplus share is not defined).

\section{Insert figure 5}

We estimated the model separately for both repeated games. Figure 5 shows that there is virtually no difference between RG1 and RG2. The influence of the surplus share is significantly positive and therefore supports the fairness-hypothesis. The prediction of a zero correlation is clearly rejected by the data.

The observed effect is statistically significant in both repeated games. However, statistical testing assumes that errors are uncorrelated, which is questionable here, since each subject was observed several times (repeated measurement). Furthermore, tests based on RG2 data are especially problematic due to the strategic interaction of subjects in RG1. To take care of the repeated measurement problem we applied the procedure suggested by Slonim and Roth (1998) to analyze RG1 data. We used a subject's average acceptance rate in periods other than the current one as an additional explanatory variable (for details see their article). However, this procedure changed the regression results only marginally. In addition, we ran a very conservative test of the fairness-hypothesis based on average data for RG1. We took a subject's mean surplus share and its acceptance rate across the six base games of RG1 and then determined the Spearman rank correlation coefficient between these variables. The correlation was positive (0.33) and significant on the 5 percent level ( $p=0.011, N=47$, one-tailed). Thus, even this very conservative test procedure supports the fairness-hypothesis. These results, therefore, give credit to 
Observation 7: The agents' acceptance decisions support the 'Fairness-Hypothesis'.

We conclude that whether or not the agent accepts the contract offered by the principal does not only depend on the implied absolute payoff but also on the implied relative payoff. We interpret this as an indication of the agent's care for fairness. It suggests that the behaviorally relevant participation constraint in PAgames is not characterized by the reservation payoff which the agent may receive outside the relationship (e.g., in the market), but is given by some payoff that captures 'fair sharing'.

How did agents who accepted a contract, react to the incentives set by the contract? To answer this question, we turn in the following subsections to the agents' actual effort behavior.

\subsection{Rational effort choices}

Figure 6 displays the distribution of actual (instead of suggested) effort decisions for all base games in which an agreement was reached. The data are shown separately for both repeated games, RG1 and RG2. ${ }^{11}$ We observe a striking similarity between the two repeated games. Obviously, experience does not affect the effort distribution very much. 60 percent of all base game effort decisions in RG1 are efficient (67 percent in RG2).

\section{Insert figure 6}

According to the game-theoretical analysis (see table 1), only the effort levels $\hat{e}_{t} \in\{0,4,8,12,16,20\}$ might be best replies for an agent with selfish preferences. Notice that this feature of our design allows for a strong test of incentive compatible behavior. To determine whether or not an effort choice might be considered (sequentially) rational, we look, in figure 7 , at the conditional effort distributions for each given theoretical prediction $\hat{e}_{t}$. In 264 base games rationality calls for $\hat{e}_{t}=20$, and in 230 of these cases (87 percent) agents did indeed choose the conditionally rational effort level. Moreover, these effort choices are also efficient. Looking at the conditional effort distribution for $\hat{e}_{t}=16$, one again finds a substantial proportion of rational choices: 20 out of 81 cases (25 percent) are conditionally rational. There is an even larger number of efficient effort choices

\footnotetext{
${ }^{11}$ Remember that a principal's suggested effort was not binding for the agent's actual choice.
} 
(35 cases, i.e., 43 percent). Thus, more than two thirds of the decisions are either best replies, or efficient. These two kinds of effort decisions (i.e., rational and efficient effort choices) are also taken more often than anything else in case $\hat{e}_{t}=12$. For the cases $\hat{e}_{t} \in\{0,4,8\}$ the best reply effort is always the modal decision, but we observe no efficient effort any longer (despite some dispersion). ${ }^{12}$

\section{Insert figure 7}

Inspecting these distributions clearly suggests the following:

Rational-Effort-Hypothesis: Effort choices are to a large degree conditionally optimal.

Table 5 shows, furthermore, that the percentage of best response effort choices increases with experience.

\begin{tabular}{|c|c|c|c|c|c|}
\hline & \multirow[b]{2}{*}{$t=$} & \multicolumn{2}{|c|}{ RG1 } & \multicolumn{2}{|c|}{ RG2 } \\
\hline & & $1,2,3$ & $4,5,6$ & $1,2,3$ & $4,5,6$ \\
\hline Rational Effort & & $53 \%$ & $61 \%$ & $66 \%$ & $76 \%$ \\
\hline Other & & $47 \%$ & $39 \%$ & $34 \%$ & $24 \%$ \\
\hline$\sum$ & & $100 \%$ & $100 \%$ & $100 \%$ & $100 \%$ \\
\hline
\end{tabular}

TABLE 5: Percentage of best reply effort choices for different levels of experience.

In order to test the Rational-Effort-Hypothesis we look at the behavior of experienced subjects in RG1. Specifically, in the last period $(t=6)$ of RG1 26 out of 39 agents (who had accepted the offered contract) chose conditionally rational effort while 13 chose some other effort. Thus the fraction of best reply choices is $\frac{2}{3}$. In principle, behavior might be driven by rationality as well as other forces; i.e., a behavioral theory might comprise various concepts. For example one might think that individuals are driven by several motivating forces at the same time and choices represent these mixed motives. Or one may think that some individuals are rational while others are not, which produces a distribution of choices

\footnotetext{
${ }^{12}$ For $\hat{e}_{t}=4$ rationality is only weakly modal, but this conditional distribution is based on just four observations.
} 
at the aggregate level. Either way, one may ask the following question: What is the lowest probability weight that such a behavioral theory may put on rational effort? More specifically: Which is the lower bound for the probability of rational choices that is compatible with the observed frequency of best reply effort, for some desired degree of confidence? Since we code effort choices binary (best reply or non-best reply), this means essentially that we are looking for a lower confidence bound for $\operatorname{prob}\left(e=e^{*}\right)$ (the probability for rational choice) based on the binomial statistic. If we fix the confidence level at 99 percent, the binomial statistic for observing 26 out of 39 best reply choices gives a lower confidence bound for $\operatorname{prob}\left(e=e^{*}\right)$ at 0.54 . Accordingly, this procedure allows us to reject the null hypothesis $H_{0}: \operatorname{prob}\left(e=e^{*}\right) \leq 0.54$ in favor of the alternative hypothesis $H_{1}: \operatorname{prob}\left(e=e^{*}\right)>0.54$ at the $1 \%$ significance level $(N=39$, one-tailed $)$.

This evidence is strong support for the Rational-Effort-Hypothesis. Remember that in each case the conditionally rational choice is given by a single effort level out of 21 possible levels. By classifying the decisions into 'rational' versus 'other' decisions our test therefore rejects a large class of behavioral theories. Every theory that induces a probability weight less than 0.54 for the rational decision can be rejected. For example, we can reject a theory that combines rationality and 'noise', if the noise level reduces $\operatorname{prob}\left(e=e^{*}\right)$ below the above threshold. The test does not use information regarding the distribution over nonrational decisions. It makes use only of the probability weight that a theory puts on the rational decision versus a non-rational decision. Since the exact distribution over non-rational decisions is irrelevant for the result of the test, this is a rather general support of the Rational-Effort-Hypothesis. ${ }^{13}$ We conclude this subsection by stating

Observation 8: Agents' effort choices support the 'Rational-Effort-Hypothesis'.

Figure 7 shows that, although a large number of effort choices can be explained by Observation 8, a non-negligible number of effort decisions deviate from the best reply effort level. In the following we investigate whether reciprocal behavior can account for them.

\footnotetext{
${ }^{13}$ The same test procedure could have been applied to the RG2 data. We abstained from statistical testing because the strategic interaction of RG1 might cause correlated errors in RG2.
} 


\subsection{Reciprocal effort choices}

As mentioned in the introduction, other studies on games that involve a PAstructure have found that effort choices can be characterized as reciprocal: contracts that are favorable for the agent trigger effort choices that are above the individually optimal effort level (positive reciprocity) whereas unfavorable contracts trigger agents' willingness to punish the principal by choosing a low effort level (negative reciprocity). In particular, in some of these experiments principals were even able to achieve high effort levels with fixed-wage contracts only. This observation suggests that, behaviorally, even fixed wages can have a positive influence on effort levels.

How does the support for the Rational-Effort-Hypothesis square with the robust observation of reciprocal behavior made in many other experiments? Figure 7 suggests that the deviations from best response effort do not appear as random; rather, agents deviated toward efficiency in many cases. Thus, we propose that the deviations depend on the agent's payoff relative to that of the principal. In our present setup, how favorable a contract for the agent is, can be measured by the surplus share the principal offers to the agent. Hence, the results from previous experiments suggest the following

Reciprocal-Effort-Hypothesis: Deviations from the best response effort level are positively correlated with the agents' surplus share.

Similar to the above analysis of rejection behavior, we determined the mean surplus share of the agent in RG1, respectively RG2, which she could have achieved by choosing conditionally rational effort; i.e., we took the mean across those periods in which she did not choose rational effort. Figure 8 displays the correlation between the agent's mean surplus share (classified in five ranges) and her average deviation from the conditionally rational effort level. The figure indicates, at least for RG1, a positive correlation as proposed by the Reciprocal-Effort-Hypothesis. The Spearman rank correlation coefficient is 0.35 in RG1. It is qualitatively as predicted and statistically significant ( $p=0.024, N=33$, one-tailed). In RG2 the coefficient is positive as well $(0.22)$. Due to the strategic interaction of the subjects, a statistical test in RG2 is problematic, however.

\section{Insert figure 8}


Hence, the results support

Observation 9: The deviations from the conditionally rational effort levels are compatible with the 'Reciprocal-Effort-Hypothesis'.

In summary, agents' behavior can be characterized as follows. Agents reject 'unfair contracts' (i.e., contracts that give them only a relatively small share of the surplus). The agents clearly react to the incentives set in the contract. Higher return shares clearly lead to higher effort choices. The agents, in particular, make conditionally rational effort choices in a large number of cases. Deviations from conditionally optimal levels can be explained with reciprocity.

\section{Summary}

In this paper we have studied behavior within a simple principal-agent experiment. Our design allowed for a large class of linear contracts, which, so far, has rarely been investigated experimentally. Principals could offer contracts with any feasible combination of positive or negative fixed wages and a return share between 0 and 100 percent. This great flexibility in contract design allowed us to study agency considerations simultaneously with issues of 'fair sharing' and reciprocity - found to be important in previous studies - within one experimental design.

Under standard economic assumptions, the optimal contract induces efficient effort. To achieve this, the contract has to provide proper monetary incentives requiring a return share that is sufficiently high. Furthermore, the theoretical model predicts agreement despite a rather asymmetric split of the surplus.

Several important features of our empirical data are, by and large, in line with orthodox economic theory. The principal designs a work contract that offers an incentive compatible return share (Observation 1), aims at implementing efficiency (Observation 2), and asks for a negative fixed wage (Observation 3). 'Selling the firm' occurs in about 30 percent the contracts (Observation 4). Almost all contracts satisfy the participation constraint (Observation 5). However, their contract offers are more fair than standard economic arguments would suggest (Observation 6). The latter two results have also been observed by Keser and Willinger (2000). Thus, the broad message from Observations 1 to 5 is that principals clearly recognize the agency problem and react accordingly but take fair sharing into account. 
The agents' behavior can be characterized by three features. First, they reject contracts that leave them with a low share of the surplus (Observation 7). This suggests that the behaviorally relevant 'participation constraint' is one that regards an 'equity constraint'. Second, agents respond, to a very large degree, optimally to the incentives set by the contracts (Observation 8). Whereas empirical analyses with field data often have difficulties to find a clear "pay-forperformance' relation (see, e.g., Prendergast 1999), we received strong support for it in the laboratory: the higher the return share, the higher has been the effort level. Third, deviations from the optimal effort level can be explained by reciprocity (Observation 9). Thus, we can conclude that return-sharing as an incentive device is "reciprocity-compatible" in the sense that the material incentives set in the contract did not destroy agents' reciprocal motivations. Reciprocity often led to efficiency-enhancing effort choices above the incentivecompatible level. This is in contrast to Fehr and Gächter (2000) who found that a simple incentive contract that stipulated a fine for detected shirking led to an almost complete 'crowding-out' of reciprocity; only a few effort choices above the incentive-compatible levels were observed. Thus, although desirable, not all incentive contracts are necessarily 'reciprocity-compatible'. Return-sharing is.

Our experiments demonstrate that 'fair sharing' and reciprocity significantly influence behavior also in more complex agency relations. Moreover, and even more importantly, these motives do not contradict optimizing behavior: Most agents were at the same time prepared to choose at least the optimal effort level, or to even go beyond it for reciprocal reasons, and to reject very unfair offers. Hence, besides assuming optimizing behavior, agency theory should also take fairness and reciprocity as important determinants of behavior into account.

Acknowledgments: This paper is part of the EU-TMR Research Network ENDEAR (FMRX-CT98-0238). We also acknowledge support by the Swiss National Science Foundation under project number 1214-051000.97 (Gächter) and by the Deutsche Forschungsgemeinschaft DFG through SonderForschungsBereich 373 (Anderhub and Königstein). We have also benefitted from comments by Armin Falk, Ernst Fehr, Urs Fischbacher, Werner Güth Peter Skott, and Shmuel Zamir and by seminar participants at the Universities of Aarhus, Karlsruhe and Zurich, at the ESA-meeting in Mannheim, the Workshop for Corporate Governance in Berlin, the IAREP Workshop in Frankfurt/Oder, the Annual Meeting of the Swiss Society for Statistics and Economics in Fribourg, and the ENDEAR workshop in Bari. We are particularly grateful to Urs Fischbacher for writing the computer program and for his support during the experiments. 


\section{References}

[1] Alston, L. and R. Higgs (1982): Contractual Mix in Southern Agriculture since the Civil War: Facts, Hypotheses, and Tests, Journal of Economic History XLII, Vol. 2, 327-352.

[2] Bewley, T. (1999): Why Wages Don't Fall During a Recession. Cambridge: Harvard University Press.

[3] Bhattacharyya, S. and F. Lafontaine (1995): Double-sided moral hazard and the nature of share contracts, RAND Journal of Economics 26, 761-781.

[4] Berg, J., L. Daley, J. Dickhaut, J. O'Brien (1986): Controlling Preferences for Lotteries on Units of Experimental Exchange, Quarterly Journal of Economics 101, 281-306.

[5] Berg, J., L. Daley, J. Dickhaut, J. O’Brien (1992): Moral Hazard and Risk Sharing: Experimental Evidence, in: Mark Isaac (ed.), Research in Experimental Economics, Vol. 5, 1-34, Greenwich: JAI Press Inc.

[6] Bull, C., A. Schotter, and K. Weigelt (1987): Tournaments and Piece Rates: An Experimental Study, Journal of Political Economy 95, 1-33.

[7] Camerer, C. (1995): Individual Decision Making, in: J. Kagel and A. Roth (eds.): The Handbook of Experimental Economics. Princeton: Princeton University Press.

[8] Camerer, C., L. Babcock, G. Loewenstein, and R. Thaler (1997): Labor Supply of New York City Cab Drivers: One Day at a Time, Quarterly Journal of Economics CXII, 407-441.

[9] Chaudhuri, A. (1998): The ratchet principle in a principal agent game with unknown costs: an experimental analysis, Journal of Economic Behavior and Organization 37, 291-304.

[10] Chisholm, D. (1997): Profit-Sharing Versus Fixed-Payment Contracts: Evidence From the Motion Pictures Industry, Journal of Law, Economics, and Organization 13, 169-201.

[11] Davis, D. and C. Holt (1993): Experimental Economics. Princeton, NJ: Princeton University Press. 
[12] DeJong, D., R. Forsythe, and R. Lundholm (1985): Ripoffs, Lemons, and Reputation Formation in Agency Relationships: A Laboratory Market Study, Journal of Finance 40, 809-823.

[13] DeJong, D., R. Forsythe, R. Lundholm, and W. Uecker (1985): A Laboratory Investigation of the Moral Hazard Problem in an Agency Relationship", Journal of Accounting Research 23 (Supplement) 81-120.

[14] Epstein, S. (1992): Testing Principal-Agent Theory, in: Mark Isaac (ed.), Research in Experimental Economics, Vol. 5, 35-60, Greenwich: JAI Press Inc.

[15] Fehr, E. and S. Gächter (1998): Reciprocity and economics: The economic implications of Homo Reciprocans, European Economic Review 42, 845-859.

[16] Fehr, E. and S. Gächter (2000): Do incentive contracts crowd out voluntary cooperation? Working Paper No. 34, Institute for Empirical Research in Economics, University of Zurich.

[17] Fehr, E., S. Gächter, and G. Kirchsteiger (1997): Reciprocity as a Contract Enforcement Device - Experimental Evidence, Econometrica 65, 833-860.

[18] Fischbacher, U. (1999): z-Tree: Zurich Toolbox for Readymade Economic Experiments. Working Paper No. 21, Institute for Empirical Research in Economics, University of Zurich.

[19] Grossman, S. and O. Hart (1983), An Analysis of the Principal-Agent Problem, Econometrica, Vol. 51, 7-45.

[20] Güth, W., W. Klose, M. Königstein and J. Schwalbach (1998): An Experimental Study of a Dynamic Principal-Agent Relationship, Managerial and Decision Economics 19, 327-341.

[21] Güth, W., M. Königstein, J. Kovács, and E. Zala (1999): Fairness within firms: The case of one principal and multiple agents, Working paper, Humboldt University Berlin.

[22] Hackett, S. (1993): Incomplete Contracting: A Laboratory Experimental Analysis, Economic Inquiry XXI, 274-297. 
[23] Hart, O. and B. Holmström (1987): The theory of contracts. in: T. Bewley (ed.), Advances in Economic Theory. Fifth World Congress. Cambridge: Cambridge University Press.

[24] Holmström, B. (1979), Moral Hazard and Observability, Bell Journal of Economics, Vol. 10, 74-91.

[25] Holmström, B. and P. Milgrom (1987): Aggregation and Linearity in the Provision of Intertemporal Incentives, Econometrica 55, 231-259.

[26] Keser, C. and M. Willinger, (2000): Principal-agent relations with hidden actions: an experimental investigation. International Journal of Industrial Organization, Vol. 18, 163-185.

[27] Loomes, G. (1998): Probabilities vs Money: A Test of Some Fundamental Assumptions About Rational Decision Making, Economic Journal 108, 477489.

[28] Mathewson, G. F. and R. Winter (1985): The Economics of Franchise Contracts, Journal of Law \& Economics XXVIII, 503-526.

[29] Nalbantian, H. and A. Schotter (1997): Productivity Under Group Incentives: An Experimental Study, American Economic Review 87, 314-341.

[30] Plott, C. and L. Wilde (1982): Professional Diagnosis vs. Self-Diagnosis: An Experimental Examination of Some Special Features of Markets with Uncertainty, in: V. Smith (ed.), Research in Experimental Economics, Vol. 2, 63-11, Greenwich: JAI Press Inc.

[31] Prendergast, C. (1999): The Provision of Incentives in Firms, Journal of Economic Literature XXXVII, 7-63.

[32] Roth, A. (1995): Bargaining Experiments, in: J. Kagel and A. Roth (eds.): Handbook of Experimental Economics. Princeton: Princeton University Press.

[33] Salanié, B. (1997): The Economics of Contracts. A Primer. The MIT Press.

[34] Selten, R.(1975): Reexamination of the Perfectness Concept for Equilibrium Points in Extensive Games, International Journal of Game Theory, Vol. 4, 25-55. 
[35] Selten, R., A. Sadrieh, and K. Abbink (1999): Money Does Not Induce Risk Neutral Behavior, but Binary Lotteries Do even Worse, Theory and Decision, Vol. 46, 211-249.

[36] Shavell, S. (1979): Risk sharing and incentives in the principal and agent relationship, Bell Journal of Economics 10, 55-73.

[37] Slonim, R. and A. Roth (1998): Learning in High Stakes Ultimatum Games: An Experiment in the Slovak Republic, Econometrica 66, 569-596. 


\section{Figures}

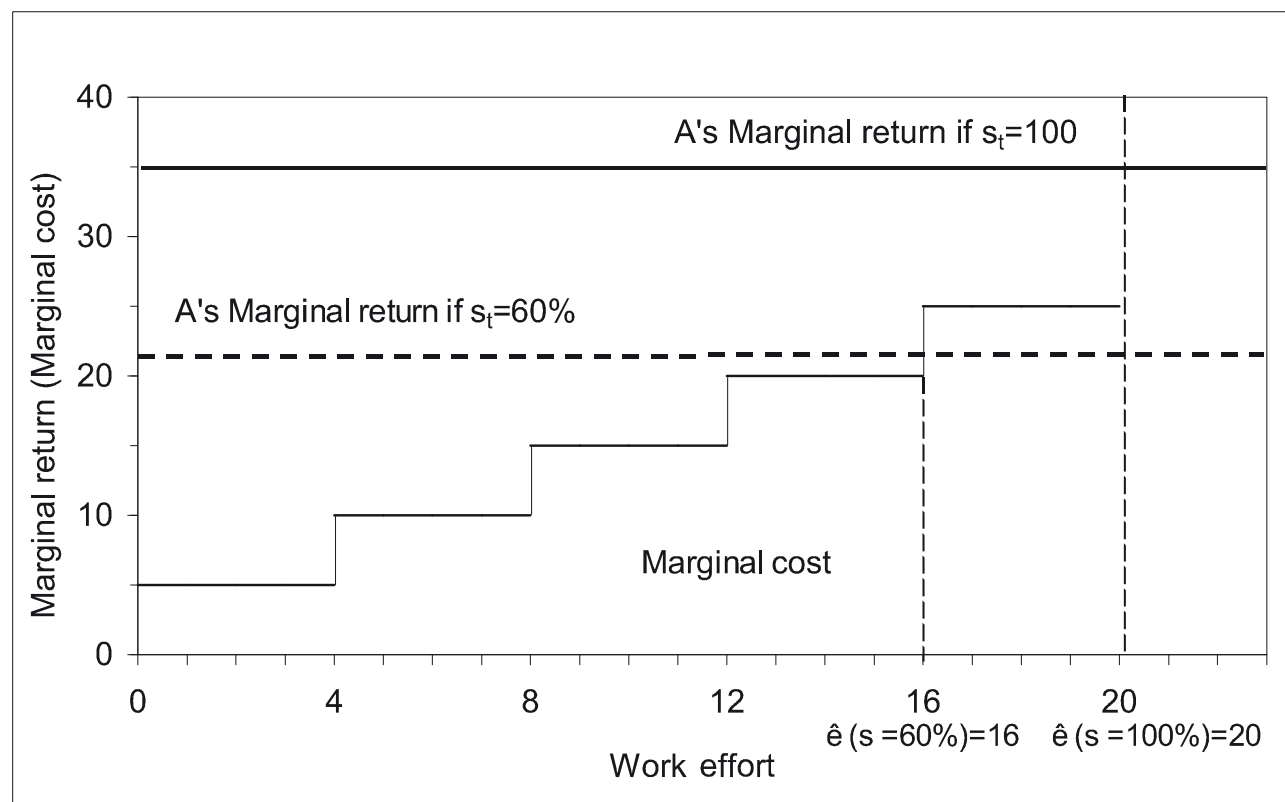

Figure 1: Marginal return function and marginal cost function as well as conditionally rational eaort choices for $s=60 \%$, respectively $s=100 \%$. 


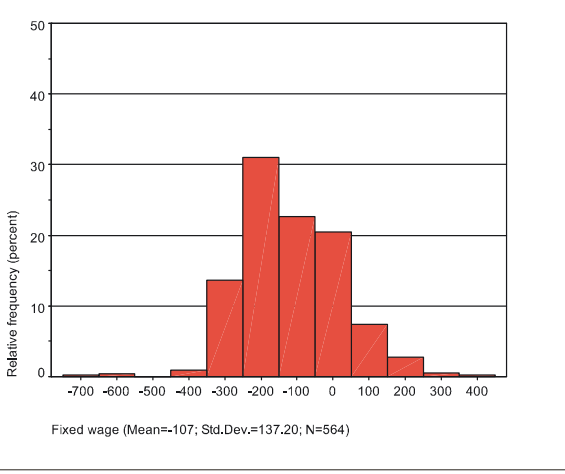

Figure 2a: Distribution of oxered ...xed wages

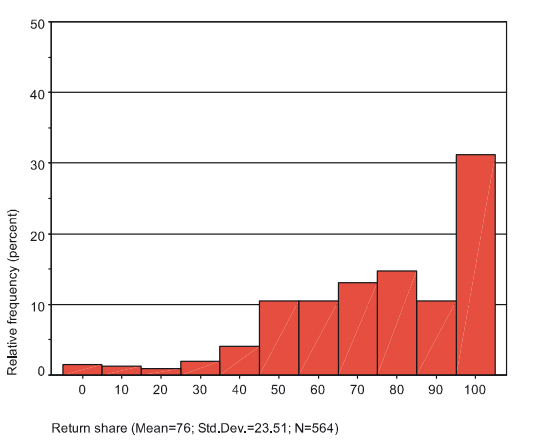

Figure 2b: Distribution of oxered return shares

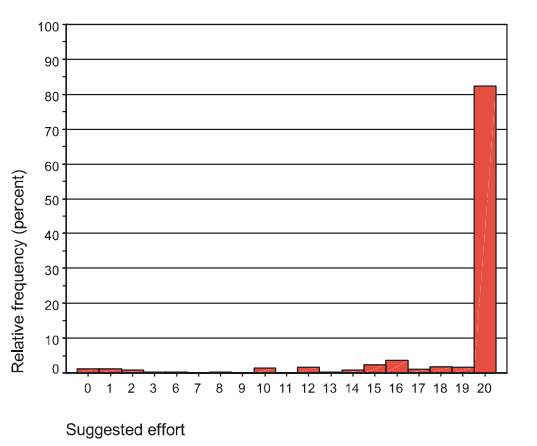

Figure 2c: Distribution of suggested eaort 


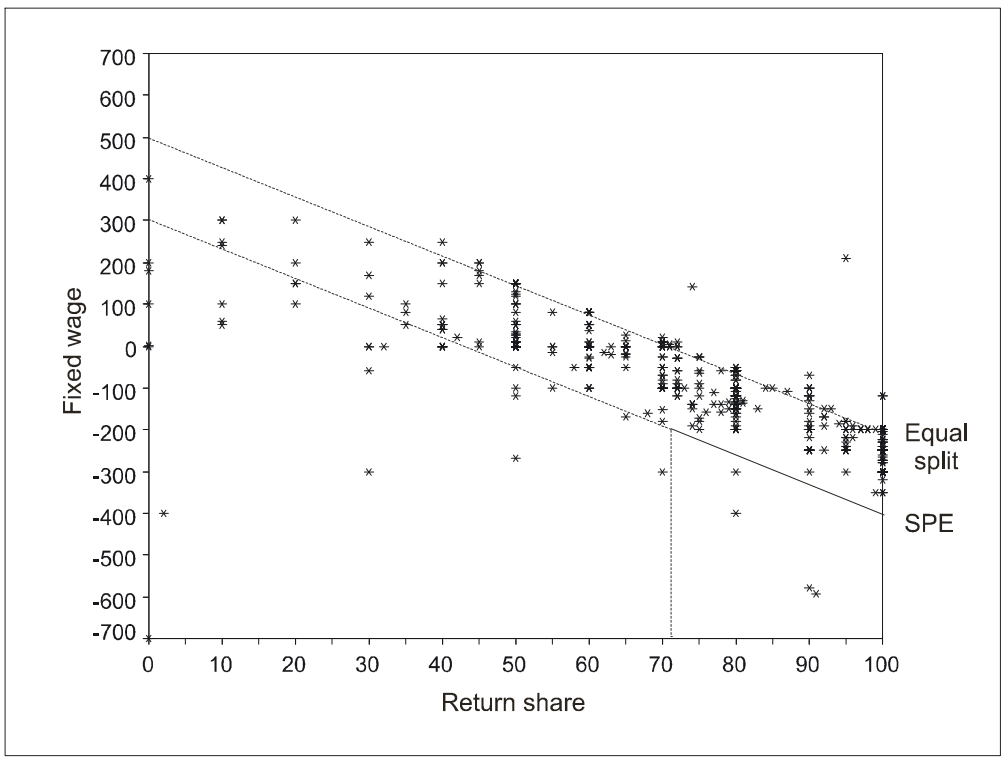

Figure 3: Combinations of return share and ...xed wage as oaered by the principals

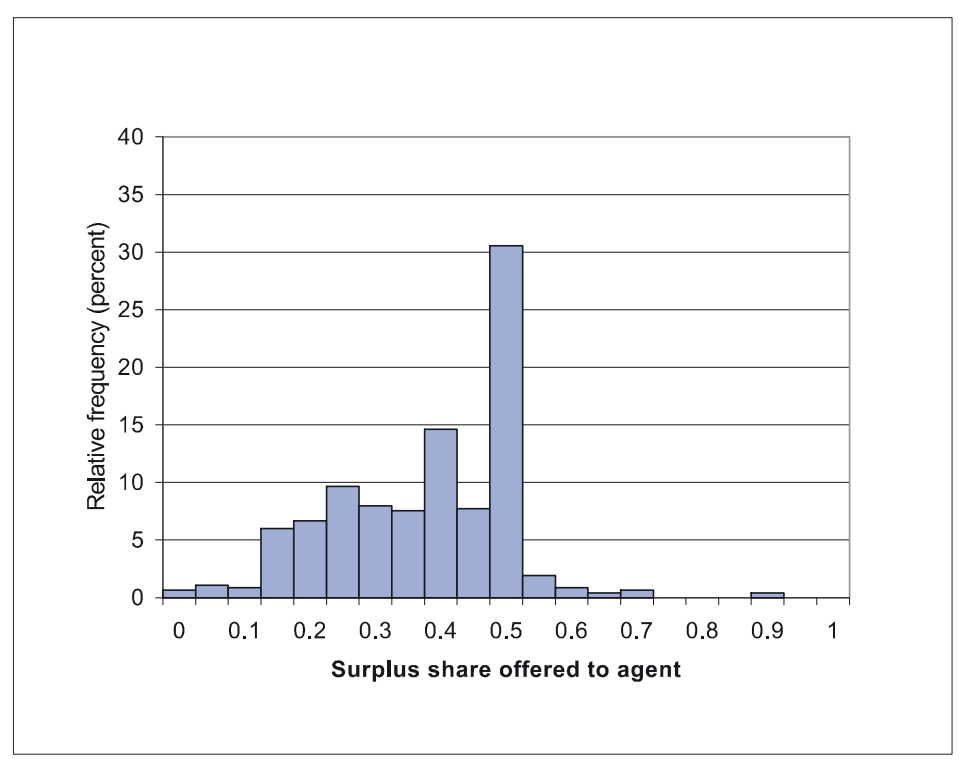

Figure 4: Surplus share oaered to the agent (for e cient contract oaers) 


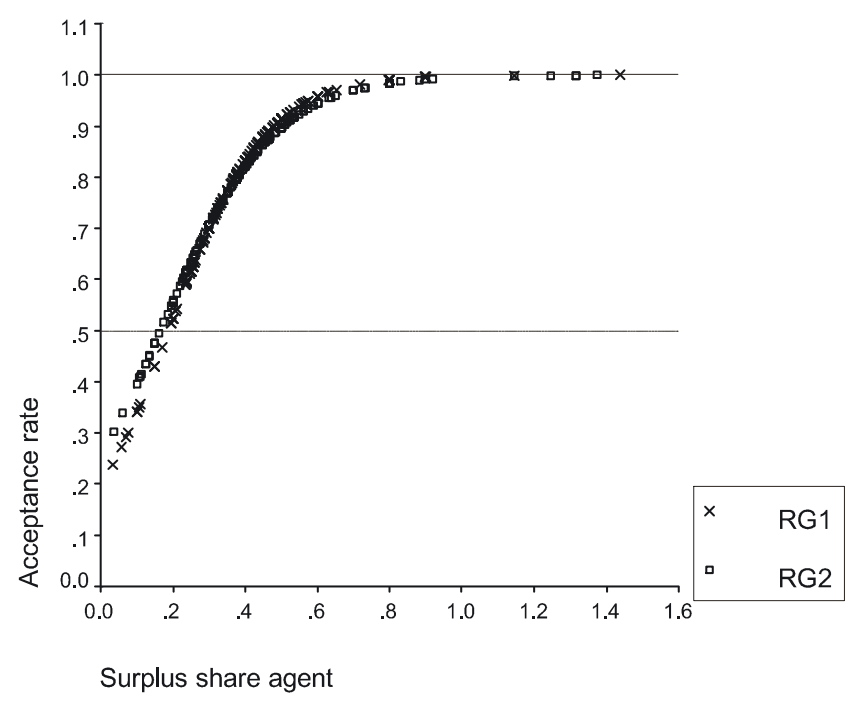

Figure 5: Predicted acceptance rate (probability of $\pm=1$ ) conditional on the surplus share oaered to the agent according to logit regressions for $R G 1$, respectively $R G 2$

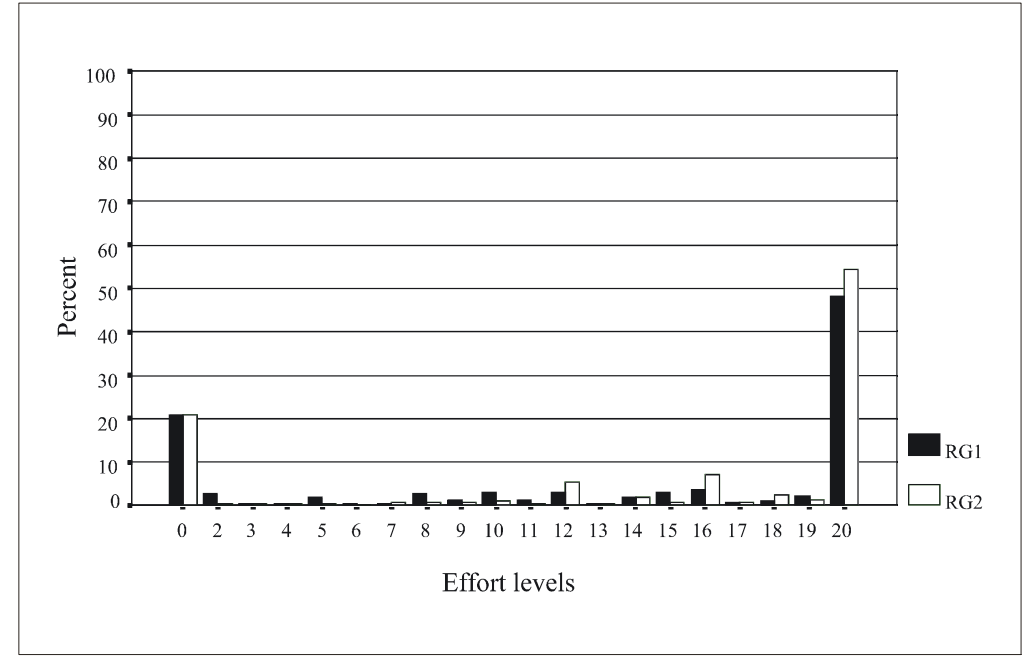

Figure 6: Frequency distribution of agents' actual exort choices in both sequences of the repeated games (RG1 and RG2) 


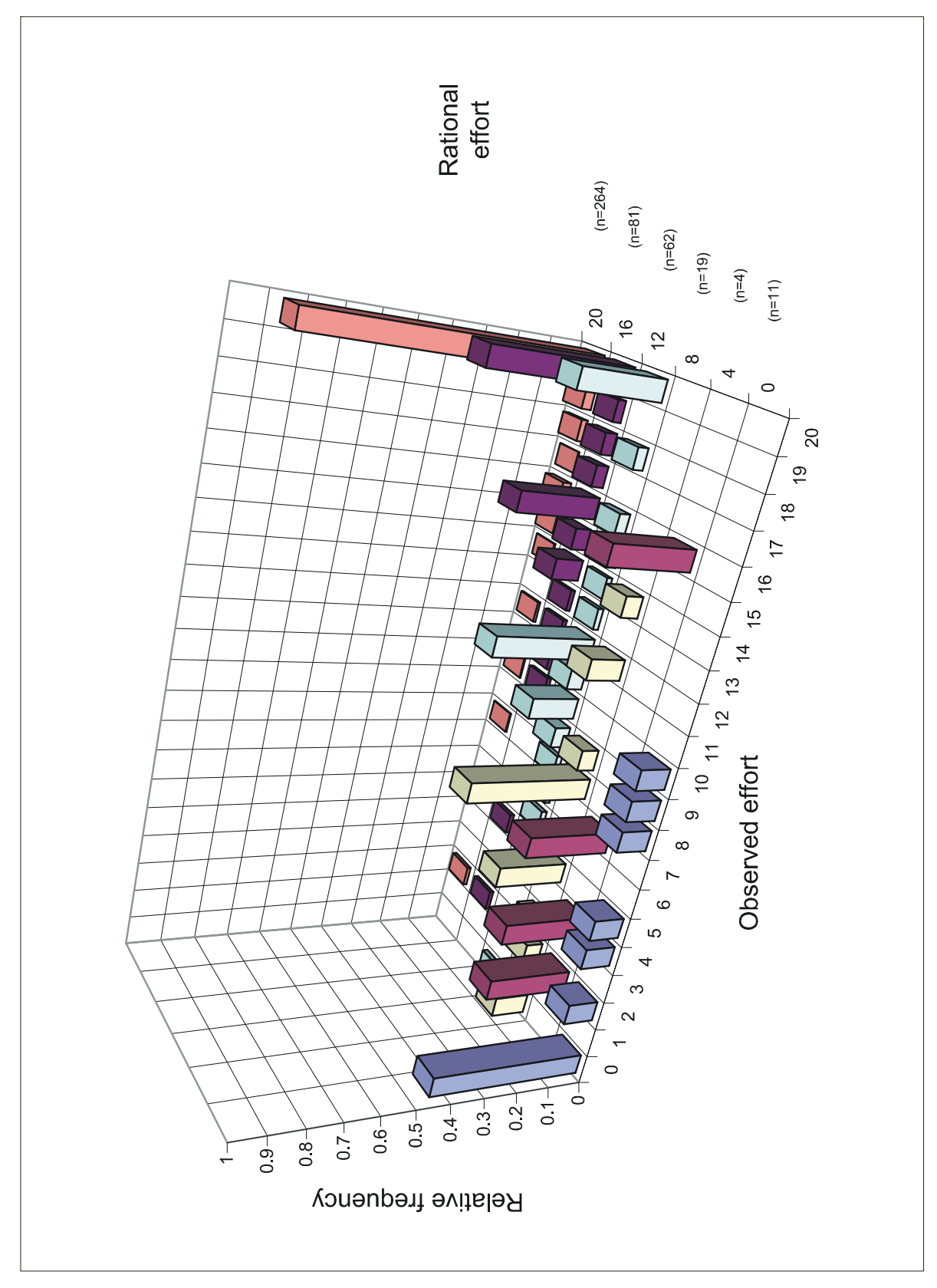

Figure 7: Conditionally rational eaort choices 


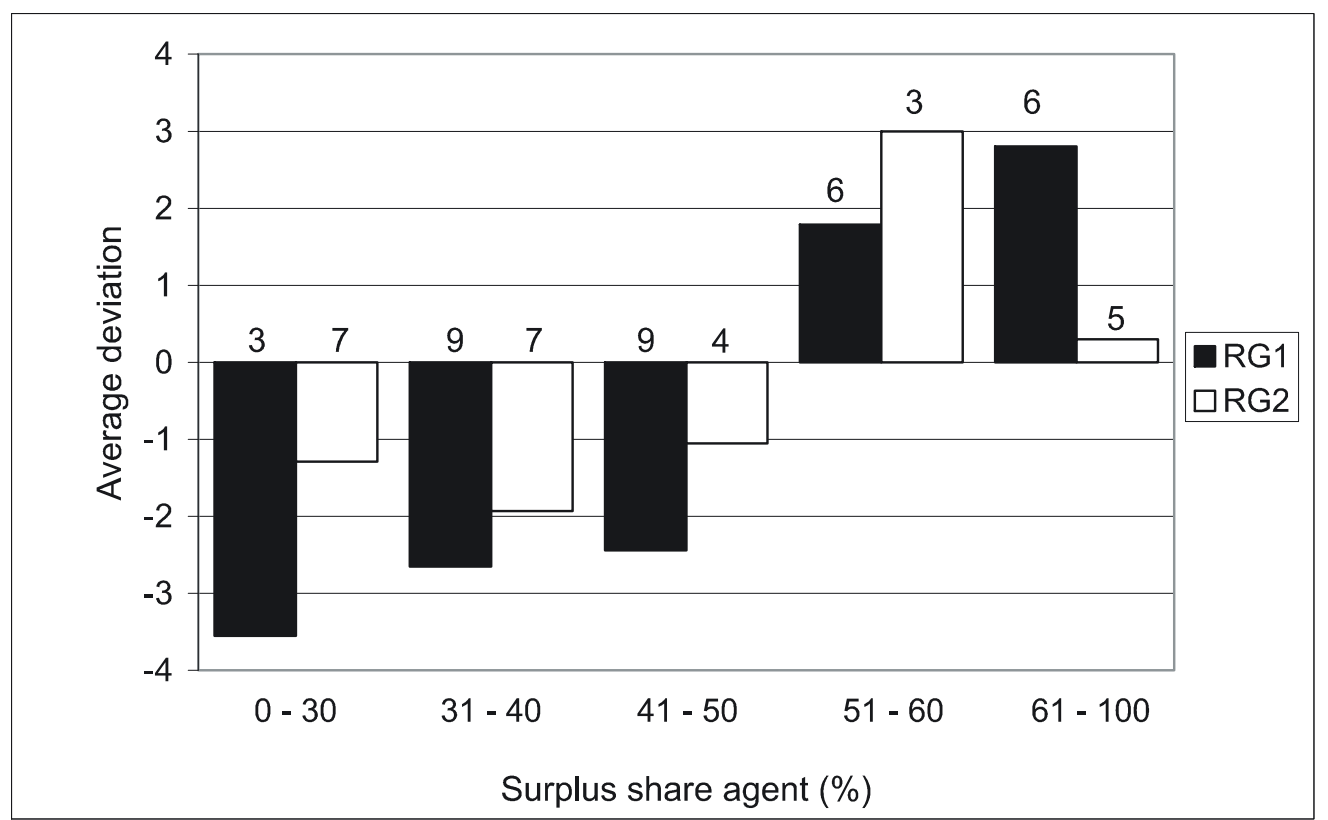

Figure 8: The number of individuals who deviated from rational eaort $(e ;$ b) for a given surplus share is indicated above the respective bar 


\title{
Appendix: Experimental instructions
}

\author{
These instructions were originally written in German. Both the principal and the agent received \\ - except for some role-specific minor details - the same instructions.
}

\section{General information}

The experiment you participate today is joint research with the Humboldt-University Berlin. It is financed by several science foundations. For your participation you will receive 15 Swiss Francs. Dependent on your decisions you can earn additional money. It is possible that some of your decisions lead to losses. You will have to finance them out of the gains from your other decisions, or, if necessary out of your show-up fee. However, you can always make decisions that avoid any losses.

During the experiment you income will be calculated in points. The exchange rate of points into Swiss Francs is

$$
1 \text { point = } 1.3 \text { Rappen } \text {. }
$$

At the end of the experiment all points you have earned will be summed up, exchanged into Swiss Francs and paid out to you in cash immediately.

Please note that during the experiment communication is not allowed. If you do have questions please raise you hand. We will answer you questions in private.

\section{Instructions}

\section{Introduction}

In this experiment you will learn about a decision problem that involves two persons. We will call them participants $\mathrm{X}$ and $\mathrm{Y}$. All participants in this experiment are allocated in two groups: the group of participants $\mathrm{X}$ and the group of participants $Y$.

\section{You belong to the group of participants $\mathrm{X}$ !}

Thus, you will decide during the whole experiment in the role of a participant $X$.

The experiment consists of 6 periods. At the beginning you will be randomly matched with a participant of group Y. You will be paired with this participant in all 6 periods. You will make your decisions at the computer. The usage of the computer will be explained to you if necessary. Your decisions will be transmitted via the computer to participant Y. This participant will only get informed about your decision. He will never learn your name or your participant number, i.e., your decisions remain anonymous.

\section{An overview of the experiment}

The experiment consists of 6 periods. It may help you to understand the decision situation if you think about the following scenario. Participant $\mathrm{X}$ decides in the role of a "firm". The "firm" has an employee (participant Y), whose work effort produces some period return. Y can choose his work effort freely in each period. Below we will explain what work effort means and how the period return comes about. However, it is true that a higher work effort leads to a higher period return, but it also causes costs that $\mathrm{Y}$ has to bear.

Y's payment is determined in an employment contract and can take place in two forms, with a fixed wage and/or a return share. The fixed wage has to be paid by participant $\mathrm{X}$ to participant $\mathrm{Y}$ independently of the period return. A 
return share means that $\mathrm{Y}$ receives an agreed share (in percent) of the return. In the following we will call these

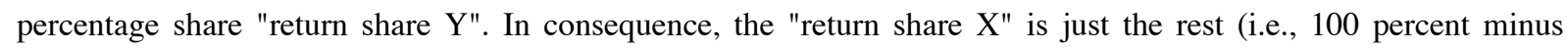
"return share $\left.\mathrm{Y}^{\prime}\right)$.

Thus, each period consists of three stages:

1. X makes, in accordance with the rules, up to two contract proposals.

2. Y chooses one contract among the possible contracts.

3. Y makes his work effort choice.

Afterwards $\mathrm{X}$ and $\mathrm{Y}$ will be paid according to the rules.

\section{The experimental details}

\subsection{Employment contract: The proposals of participant $X$}

At the beginning of each period, first an employment contract will be determined. For the contract design the following holds:

- In each period there is a so-called "status quo"-contract that becomes effective if there is no agreement about a new contract. The "status quo"-contract consists of a fixed payment of 0 and a "return share Y" of 0 . This "status quo"-contract is the same in each period.

- In addition to the "status quo"-contract in each period X can

- in the first period make up to two new contract proposals

- in each of the later periods make one new contract proposal.

Y decides whether he accepts the new contract proposal (or which of the new proposals he accepts, respectively), or whether the "status quo"-contract shall become valid.

- Each contract proposal by $\mathrm{X}$ also contains a desired work effort that, however, is not binding for $\mathrm{Y}$.

A contract proposal consists of three components: a fixed wage, a "return share $\mathrm{Y}^{\text {" }}$ and a desired work effort. Participant $\mathrm{X}$ is - in the bounds of the rules given below - completely free in the design of the contract proposals.

- It is possible to agree on a positive or a negative fixed wage. If the fixed wage is positive, this means that participant $\mathrm{Y}$ gets this wage from participant X, regardless of the period return. A negative fixed wage means that $\mathrm{Y}$ has to pay that amount to $\mathrm{X}$, regardless of the period return.

- The "return share $\mathbf{Y}^{\prime}$ is expressed in percentage points. It says how large Y's share - in percent - of the total period return is. Participant $\mathrm{X}$ gets the rest ("return share $\mathrm{X}$ " $=100$ percent minus "return share $\mathrm{Y}^{\prime)}$ ).

- $\mathrm{X}$ 's desired work effort is not binding for Y.

\section{For the contract design the following rules hold:}

$$
\begin{gathered}
-700 \leq \text { fixed wage } \leq 700 \\
0 \leq \text { "return share } \mathrm{Y} \text { " } \leq 100 \text { (in percent) } \\
0 \leq \text { desired work effort } \leq 20
\end{gathered}
$$

Only integer numbers are possible!

In designing the contracts ALL combinations that are compatible with these rules are possible! 
To make the rules clear to you, we depict the screen that will be shown to $\mathrm{X}$ at the beginning of period 1:

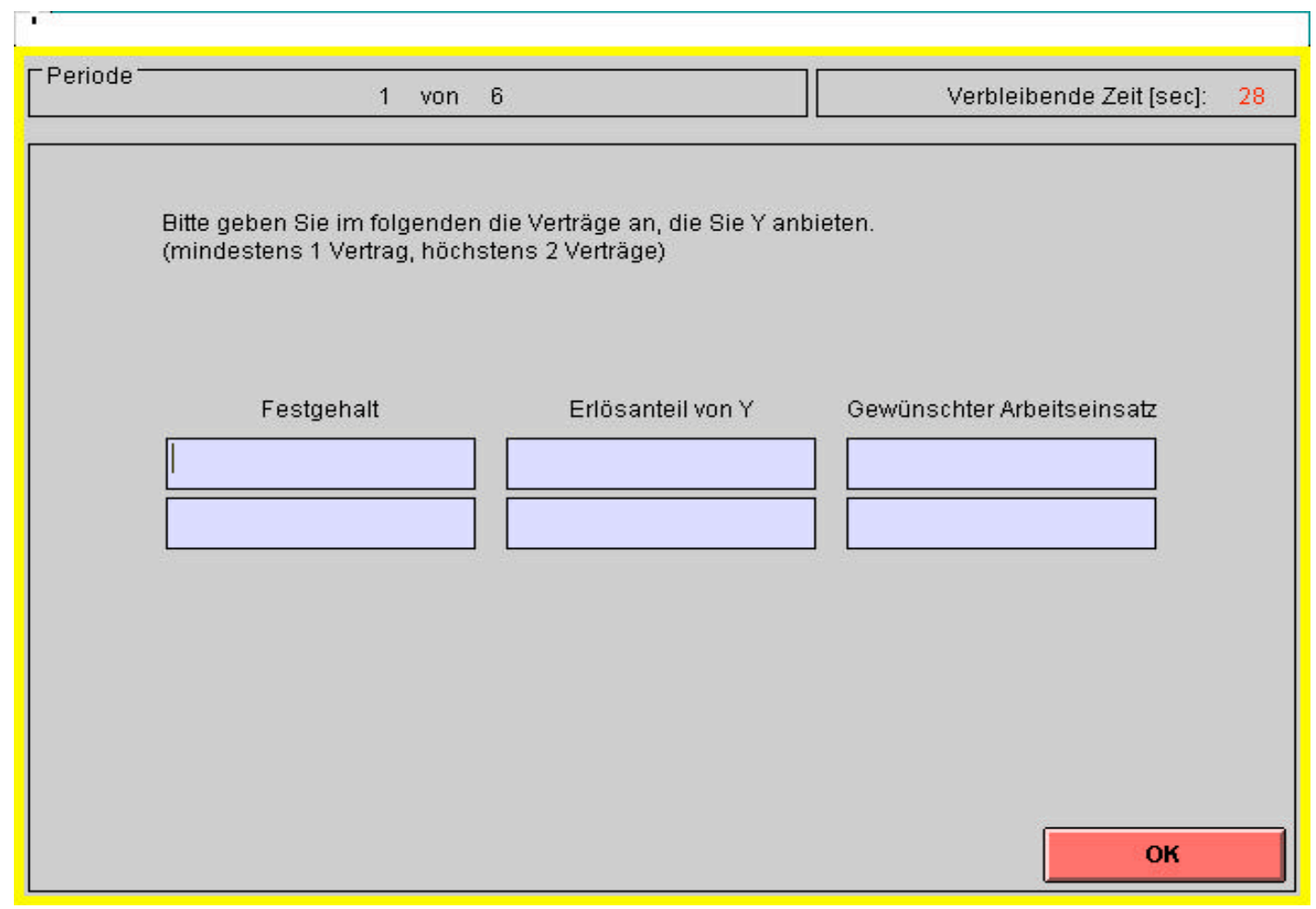

On this screen (as well as in all other screens in which you have to make a decision) you see the current period number at the top left and at the top right the remaining time. Participant $\mathrm{X}$ now has the possibility to make up to two contract proposals by just entering them into the corresponding boxes. The screen for the subsequent periods is very similar except that participant $\mathrm{X}$ can only propose one new contract.

\subsection{Employment contract: The choice by participant $Y$}

Participant $\mathrm{Y}$ chooses among the available contracts. In period $1 \mathrm{Y}$ can choose between the "status quo"-contract (,fixed wage of 0 ["Festgehalt"], return share Y ["Erlösanteil von Y"] of $0 \%$ ") and contract 1 or contract 2, and in all other periods between the "status quo"-contract or a new contract.

\subsection{Work effort of participant $Y$}

After Y has chosen a contract, he determines his work effort. The desired work effort ["gewünschter Arbeitseinsatz"] stated by participant X in the contract is not binding for participant $\mathrm{Y}$. The work effort is expressed as a number. In the enclosed table all possible work efforts (all integer numbers between 0 and 20) as well as the produced returns are given. The table also contains the costs of the work effort that $\mathrm{Y}$ has to bear. The higher the work effort, the higher is the return but the higher are also the costs of the work effort.

\subsection{Period payoffs and end of period}

After participant $\mathrm{Y}$ has entered his work effort into the computer, the period gains will be calculated according to the formulas stated on the enclosed table. 
Afterwards both participants will be informed about the decisions (work effort, fixed wages, "return share $\mathrm{Y}^{\prime \prime}$ ), own period payoff and the sum of the own payoffs so far. This ends a period and the next one starts.

\section{Control questionnaire}

The following control questions are only designed to test your understanding of the payoff calculations. You should learn - with the help of some arbitrary examples - how the payoffs of $X$ and $Y$ change if the terms of the contract, or the work effort changes. In the experiments you are in no way bound by these examples!

1. Y accepts the following contract: fixed wage: 580, return share $\mathrm{Y}: 10 \%$. Calculate the payoffs of $\mathrm{X}$ and $\mathrm{Y}$ if $\mathrm{Y}$ chooses a work effort of 2.

Payoff X: Payoff $Y$ :

2. The same as 1., but $Y$ chooses a work effort of 18 .

Payoff X:

Payoff Y:

3. $\mathrm{Y}$ accepts the following contract: fixed wage: 580, return share $\mathrm{Y}: 90 \%$. Calculate the payoffs of $\mathrm{X}$ and $\mathrm{Y}$ if $\mathrm{Y}$ chooses a work effort of 2.

Payoff X:

Payoff Y:

4. The same as 3., but $Y$ chooses a work effort of 18.

Payoff X:

Payoff Y:

5. $\mathrm{Y}$ accepts the following contract: fixed wage: -580, return share $\mathrm{Y}: 10 \%$. Calculate the payoffs of $\mathrm{X}$ and $\mathrm{Y}$ if $\mathrm{Y}$ chooses a work effort of 2.

Payoff X:

Payoff Y:

6. The same as 5., but $Y$ chooses a work effort of 18 .

Payoff X:

Payoff Y:

7. $\mathrm{Y}$ accepts the following contract: fixed wage: -580 , return share $\mathrm{Y}: 90 \%$. Calculate the payoffs of $\mathrm{X}$ and $\mathrm{Y}$ if $\mathrm{Y}$ chooses a work effort of 2.

Payoff X:

Payoff $\mathrm{Y}$ :

8. The same as 7., but $Y$ chooses a work effort of 18 .

Payoff X:

Payoff Y:

9. $\mathrm{Y}$ accepts the following contract: fixed wage: 120 , return share $\mathrm{Y}: 0 \%$. Calculate the payoffs of $\mathrm{X}$ and $\mathrm{Y}$ if $\mathrm{Y}$ chooses a work effort of 0 .

Payoff X:

Payoff Y:

10. Y accepts the following contract: fixed wage: -120 , return share $\mathrm{Y}: 100 \%$. Calculate the payoffs of $\mathrm{X}$ and $\mathrm{Y}$ if $\mathrm{Y}$ chooses a work effort of 20.

Payoff X:

Payoff Y:

11. Y accepts the "status quo"-contract: fixed wage: 120 , return share Y: $0 \%$. Calculate the payoffs if Y chooses a work effort of 0 .

Payoff X:

Payoff Y: 
Work effort, return of the work effort and costs of the work effort for Y:

\begin{tabular}{|c|c|c|}
\hline Work effort: & $\begin{array}{c}\text { Total period return from work } \\
\text { effort }\end{array}$ & costs of work effort for $\mathbf{Y}$ \\
\hline 0 & 0 & 0 \\
\hline 1 & 35 & 5 \\
\hline 2 & 70 & 10 \\
\hline 3 & 105 & 15 \\
\hline 4 & 140 & 20 \\
\hline 5 & 175 & 30 \\
\hline 6 & 210 & 40 \\
\hline 7 & 245 & 50 \\
\hline 8 & 280 & 60 \\
\hline 9 & 315 & 75 \\
\hline 10 & 350 & 90 \\
\hline 11 & 385 & 105 \\
\hline 12 & 420 & 120 \\
\hline 13 & 455 & 140 \\
\hline 14 & 490 & 160 \\
\hline 15 & 525 & 180 \\
\hline 16 & 560 & 200 \\
\hline 17 & 595 & 225 \\
\hline 18 & 630 & 250 \\
\hline 19 & 665 & 275 \\
\hline 20 & 700 & 300 \\
\hline
\end{tabular}

Period payoff Y:

return share $\mathrm{Y}[=$ "return share $\mathrm{Y} " / 100 \cdot$ return]

+ fixed wage

- costs of work effort

Period payoff X: $\quad$ return share $X\left[=\left(\left(100-\right.\right.\right.$ "return share $\left.\left.\mathrm{Y}^{\prime \prime}\right) / 100\right) \cdot$ return $]$

fixed wage

Please note: the return share is given in percentages and shares the period return between $\mathrm{X}$ and $\mathrm{Y}$. 